\title{
Editorial
}

Gene Therapy (2004) 11, 427-428. doi:10.1038/sj.gt.3302237

\section{Gene therapy: cornerstone of modern medicine in the new millennium?}

In November 2003, the UK's Gene Therapy Advisory Committee (GTAC) presented a public meeting entitled 'Gene Therapy - Cornerstone of modern medicine in the new millennium?' Although the meeting was held at the European Society for Gene Therapy's annual conference, the audience comprised both specialists and laypeople, from research scientists to interested school students and parents of children with diseases for whom gene therapy could be the only potential hope for treatment. This make-up reflects the broad base that the committee draws from to provide balanced and considered advice on the acceptability, implications and ethics of gene therapy research proposals, and to provide advice to UK Health Ministers.

Communicating to such a wide audience is never easy, but the various presentations avoided direct discussion of hard science, and focused on the wider issues surrounding gene therapy in the public arena. The principles of gene therapy were covered in Professor Norman Nevin's opening reflections on 10 years of gene therapy in the UK. This included what the technology was originally envisaged to provide, that is, treatment for inherited disorders such as cystic fibrosis, and explained that the current focus is now overwhelmingly on cancer treatment, which accounts for $74 \%$ of all UK trials to date. GTAC's responsibility is partly to monitor the trends of the various approaches and how the UK stands in comparison to progress being made in Europe and the rest of the world. The USA currently leads in quantity of trials by a strong margin, but within Europe, the UK is the outright leader, responsible for $65 \%$ of European trials. Setting the tone for the rest of the presentations, Professor Nevin concluded that the present success rate for gene therapy, 'is modest, but [...] we can look forward to an exciting future'.

Sharing this optimism was Rosie Barnes, Chief Executive of the Cystic Fibrosis Trust and former member of GTAC. There have been many pitfalls in developing a gene therapy to help stop $\mathrm{CF}$ from being a life-threatening condition: early optimism from when the CFTR gene was discovered in 1989 has been tempered by the challenge of finding funding to support the UK Gene
Therapy Consortium. The Consortium works to identify suitable vectors and modes of delivery and to overcome the problems of toxicity and short-lived expression. In the UK at least, the Consortium is a working model favoured by the Government, as three groups are working together without duplication of effort, and with an increased trust between members. While research into gene therapies for $\mathrm{CF}$ has a long way to go before any leaps in return are seen, the current state is encouraging.

Of course, severe combined immunodeficiency (SCID) has been a high-profile focus of more recent gene therapy trials, and was used here to illustrate parents' perspectives on gene therapy. Without a bone marrow transplant, SCID is usually fatal in patients by 2 years of age. Whether to go ahead with a transplant, which is more likely to succeed when the child is fit and healthy, is a terrifying choice for a parent to make, as it is such a brutal and risky process. Some children do not have this option at all, as a suitable transplant match is not always available. In these cases, gene therapy is almost the only option. While the outcome of the Paris trials was a wellknown disappointment, halting the trials in France but not in the UK, Fiona Sandford - GTAC member and parent of a child born with a combined immunodeficiency - explained that, for parents, gene therapy is a better option and a more hopeful prospect. Aside from the therapy itself being less aggressive and presenting fewer risks than a mismatched bone marrow transplant, it can be given to a sicker child. Parents do not have to weigh up the decision of giving harsh treatment to their child during a rare healthy phase. Further still, being able to treat genetic disorders resolves many of the ethical issues surrounding preimplantation diagnosis, terminations and trying for siblings to provide a bone marrow match.

Gene therapy, as a new technology, has thrown up countless ethical issues, of which the above are just a few. Dr Richard Ashcroft, head of the Medical Ethics Unit at Imperial College London, explained how ethical debates surrounding genetic modification have changed since the 1960s. A number of important issues are currently agreed upon, more or less consistently: that germline modification should be, and is, prohibited; that therapies are distinct from enhancements - the former being favoured and the latter not; that experimental therapies and trials need careful monitoring throughout their duration. Other issues emerge as the technologies develop and are more thoroughly understood; the ethical debate must keep pace with such developments. Current hot issues are the safety and regulation of the therapies, both research and treatment; the place gene therapy will take 
in the therapeutic and preventative medical arsenal; constantly evaluating the trade-off of risk against benefits to both patients in trials and future patients. Our understanding and priorities will be constantly changing, but must always be challenged.

Dr Geoff Watts, a scientific broadcaster, rounded up the discussion with cautionary tales of how the media could make or break the public view of gene therapy technology, and how that can affect its future development. The morning's presentations illustrated the level of complexity involved, not only in the science, but also in the technology's many applications and repercussions, which could potentially confuse and damage the press' and public's understanding. As the gene therapy approach to disease is so novel, the press and public need to remain open minded to allow research and the exploration of applications to continue without the mishandling and public outcry that has accompanied the GM food debate.

In all, the morning's presentation was well received, and gave a refreshing look at the issues surrounding the activity of scientists engaged in research and clinical trials, serving as an important reminder of the wider context of gene therapy. The meeting was part of GTAC's commitment to annual public meetings. Details can be found at GTAC's website: http://www.doh.gov.uk/ genetics/gtac

Jenny Jacoby 